\title{
XXXIX. The spectrum of cyanogen
}

\section{E.C.C. Baly F.I.C. \& H.W. Syers M.A. M.D.}

To cite this article: E.C.C. Baly F.I.C. \& H.W. Syers M.A. M.D. (1901) XXXIX. The spectrum of cyanogen, Philosophical Magazine Series 6, 2:10, 386-391, DOI: 10.1080/14786440109462705

To link to this article: http://dx.doi.org/10.1080/14786440109462705

$$
\text { 册 Published online: } 08 \text { Jun } 2010 .
$$

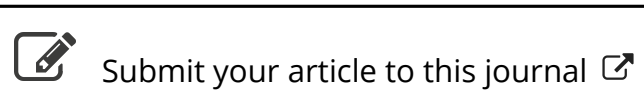

\footnotetext{
Цll Article views: 5
}

Q View related articles $\square$

Citing articles: 1 View citing articles $\square$ 
are known to be functions of the magnetic field, and the effect of the field upon their three space-components is well known.

The constants $\mathrm{C}_{1}, \mathrm{C}_{2}, \ldots \mathrm{C}_{m}$ determine the relative intensities of the maxima but not their form or position, since they do not occur in the derivatives of the function. Both the position and the form of the finite maxima depend on the values of $B$ and $n$, and the latter at least depends upon the distribution of the ionic or molecular periods about the mean. Both these parameters appear to be a minimum for perfect radiators. $B$ and perhaps $n$ also are functions of the pressure when this is variable.

It is hoped that this rather desultory diseussion of the critical properties of the complete emission function may prove useful and suggestive in the further investigation of the emission of partial radiators. It may be indicative of the possible great practical value of the discussion of physical functions from the standpoint and by the methods of modern mathematical function theory. The results obtained are of course only tentative at best, and liable to be greatly modified by new experimental evidence, yet the same may be said of elaborate analytical deductions.

Berkeley, California, A pril 1901.

XXXIX. The Spectrum of Cyanogen.

$E y$ E. C. C. BaLY, F.L.C., and H. W. Syers, M.A., M.D)**

IN a recent paper in the Philosophical Magazine on the 1 Spectra of Carbon $\dagger$, Professor Smithells pointed out the desirability of observing the vacuum-tube spectrum of cyanogen, with particular reference to the presence or absence of the spectra of carbon, inasmuch as their absence would materially support the explanation he puts forward as to their origin, namely, that the carbon-oxide spectrum is due to carbon dioxide, and the Swan spectrum to carbon monoxide, while the line spectrum is due to the element carbon.

One of us in a previous paper + , some years back, in dealing with the stratification of the electric discharge, described experiments which had been made on mixtures of hydrogen and carbon dioxide and referred to the spectra seen as those of hydrogen and carbon dioxide. This has since been criticised

* Communicated by the Physical Society : read June 28, 1901.

$\dagger$ Phil. Mag. April 1901.

$\ddagger$ Baly, Phil. Mag. xxxv. p. 200 (1893). 
severely*, because in the general opinion of spectroscopists carbon dioxide has no spectrum at all.

A great number of experiments, however, had been previously carried out with a view of obtaining a mixture of hydrogen and carbon monoxide, or rather a mixture which showed only the Swan spectrum together with that of hydrogen. This was found at the time to be impossible, as the Swan spectrum was at once changed into the carbonoxide spectrum.

In order to obtain the Swan spectrum in a pure state, it was found necessary to fill a vacuum-tube with pure carbon monoxide, using the greatest precautions to eliminate all impurities, as the smallest trace of oxygen at once changed the spectrum to the carbon-oxide spectrum, which itself was always obtained when carbon dioxide was used.

These results were not published at the time as they did not actually bear on the work in hand; but in view of Professor Smithells's recent paper, it seems worth while to describe them and others more recently carried out, since they support very strongly the view he puts forward. There seems, indeed, no room for doubt that the true explanation of these spectra is that they are due to carbon monoxide and dioxide respectively, but at the same time it is easy to see how confusion could arise. In the first place, there is the extreme difficulty of obtaining a vacuum-tube containing pure carbon monoxide; and in the second place, a very small quantity of carbon dioxide in a mixture gives a very decided spectrum, and can easily mask that of carbon monoxide. These two facts can account for all the difficulty connected with the vacuum-tube spectra of the gases, because under ordinary circumstances carbon monoxide is changed so far into carbon dioxide that it shows none, or only very little, of the Swan spectrum, but practically entirely the carbon-oxide spectrum. Naturally, therefore, the carbonoxide spectrum was attributed to carbon monoxide.

As Professor Smithells has shown, if proper precautions are taken, then carbon monoxide gives the Swan spectrum, and when pure only the Swan spectrum. The chief difficulty lies in removing all the condensed air from the walls of the vacuum-tube, and all the occluded gases from the electrodes. This can be done quite easily by exhausting as far as possible, keeping the discharge passing and heating the vacuum-tube with a Bunsen-burner. The carbon monoxide must be made from formic acid and sulphuric acid, and should preferably

* Kayser, Handbuch der SFestroscopie, p. 198. 
be let into the vacuum-tube directly from the generating apparatus.

Even with the above precautions, the first admission of the gas often gives no Swan spectrum; but after re-exhaustion and re-admission once or twice more, the Swan spectrum is seen unmixed with the carbon-oxide spectrum. This experiment bas been repeated very many times in various ways, and with always identically the same result.

It is interesting also to note that, under certain conditions, the carbon monoxide deposits carbon under the influence of the discharge ; this is always at once accompanied by a change in the spectrum to the carbon-oxide spectrum. Again, the admission of a small trace of oxygen into a vacuum-tube showing the Swan spectrum, instantaneously changes it to the carbon-oxide spectrum. These facts are strongly confirmatory of the theory.

As regards the carbon-oxide spectrum, this is invariably obtained when the electric discharge is passed through either carbon dioxide itself, or a mixture of carbonic oxide and oxygen.

As Professor Smithells has pointed out, considerable support would be gained to the above view of the carbon spectra, if it could be shown that a carbon compound such as cyanogen gives no Swan spectrum when under the influence of the electric discharge. Smithells was unable to sutisty himself as regards this, owing to the inherent difficulties in working with cyanogen; but, by taking similar precautions as were described above, we have succeeded in filling vacuum-tubes with cyanogen which showed no trace of either of the carbon spectra, but only a very beautiful and characteristic cyanogen spectrum. In these experiments, the first difficulty to be overcome was in connexion with the purity of the cyanogen itself. This was overcome as follows:-About half a litre of the gas was prepared as pure as possible by heating mercuric cyanide, and this was then frozen in a small bulb immersed in liquid air. The bulb containing the cyanogen was then exhausted as far as possible with a mercury-pump, and the liquid air being then removed, the cyanogen was allowed to boil off into a gas-holder. A second difficulty was the very rapid polymerization to paracyanogen, which takes place when the discharge is passed through the gas; this was, however, surmounted by allowing a slow stream of cyanogen to flow into the vacuum-tube.

The apparatus used is shown in the figure, where $A$ is the tube containing the mercuric cyanide, and $\mathrm{B}$ a mercury gasholder to which was fitted a reservoir and indiarubber tubing 
on the tube $\mathrm{M}$, while $\mathrm{C}$ is the bulb in which the gas was frozen. The gasholder B was provided with a three-way stopcock D, one arm of which was connected to the cyanogensupply apparatus, and the other to one end of the vacuumtube E. The other end of the vacuum-tube was connected to the pump through the tap F, and the cyanogen supply apparatus was also connected to the pump through the tap $G$.

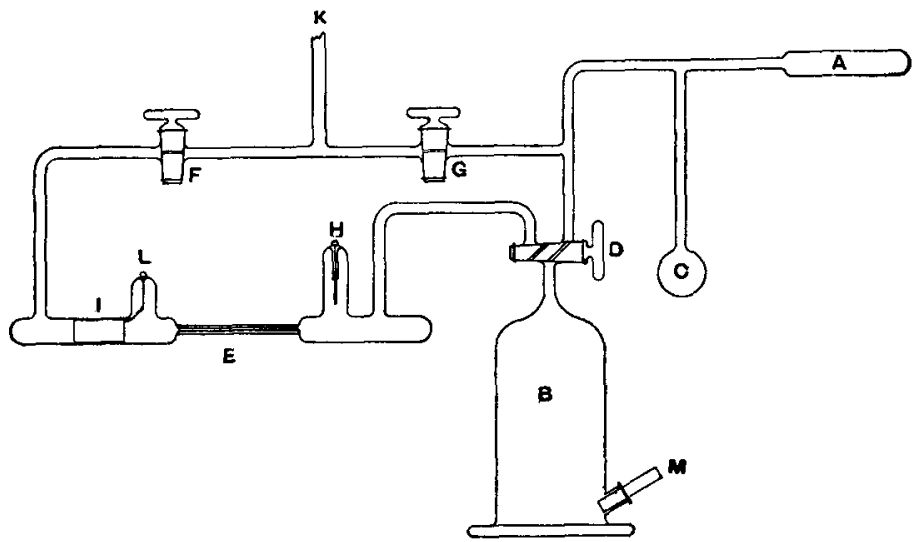

On account of the very rapid deposition of paracyanogen on the walls of the vacuum-tube when the discharge is passed through cyanogen, it was found impossible to examine the spectrum of the discharge in the usual way, as the brown deposit became rapidly quite opaque. It was necessary therefore to observe the discharge "end on," and the tube was arranged as shown in the diagram. The electrode I was made in the shape of a bollow cylinder of sheet-aluminium, which fitted tightly into the tube and enabled the spectrum of the negative glow to be examined if desired. Connexion was made with $I$ by a platinum wire sealed in at $L$. The other electrode was of aluminium wire of the usual design, and was sealed in at $H$. Connexion was made with a mercury-pump through the tube $K$, and in this way both parts of the apparatus could be separately exhausted.

The first stage of course was to prepare the pure cyanogen, which was earried out as follows:- The gasholder B was nearly emptied of mercury, which was run into the reservoir and the indiarubber tube tightly clipped. The three-way tap D was turned so as to connect the gasholder with the cyanogen apparatus, and the whole was exhausted as far as possible through the tap $G$. In this way all the condensed Phil. Mog. S. 6. Vol. 2. No. 10. Oct.1901. 2 D 
gases were removed from the cyanide of mercury and the walls of the gasholder. The tap G was then closed, and the cyanide in A strongly heated until sufficient cyanogen had collected to fill the gasholder. The bulb $\mathrm{C}$ was then immersed in liquid air, and all the eyanogen frozen therein; the tap $G$ being then again opened, any gas left unliquefied was pumped away, it being found that the exhaustion could bo carried very high, as the solid cyanogen has such an extremely low vapour-pressure at the temperature of boiling air. The tap $G$ was then again closed, and the cyanogen allowed to boil back into the gasholder.

The second stage was to exhanst the vacuum-tube as far as possible, with the discharge passing during the whole time, in order to remove every trace of gas from all parts of the tube. When this process bad been effectively carried out, small quantities of cyanogen were admitted and pumped out again, the spectrum being examined after each admission. At first the carbon spectra were seen together with the nitrogen spectra, showing undonbtedly that oxidation of the cyanogen was taking place. This, however, became less and less crident, and finally we were able to obtain a spectrum absolucely free from the carbon and nitrogen spectra. The spectrum obtained was extremely benutiful, and differs from the flame-spectrum of cyanogen. It presents a series of equidistant flutings through the whole of the red and yellow, somewhat recalling those of the positive band-spectrum of nitrogen. The cyanogen bands are, however, much wider than the nitrogen bands, and do not show the cbaracteristic break in the orange seen in the nitrogen spectrum. The flutings under higher dispersion are of course split into series of very fine lines.

The polymerization of the cyanogen was so rapid as only to allow the observations to last a few seconds after the admission of the gas. We succeeded, however, in overcoming this difficulty by allowing a constant slow stream of cyanogen to pass into the tube, and in this way were able to take careful observations. That the brown deposit on the vacuum-tube is paracyanogen, can easily be proved by its volatility at a high temperature.

It is worth while also to point out, that the admission of oxygen or air into the vacuum-tube during the experiments was at once attended by the appearance of the carbon spectra.

In conclusion, these experiments tend to prove that

(1st) The Swan spectrum is not produced by a carbon ccmpound which does not contain oxygen; whence it follows that 
Transmission of Emanations of Phosphorus through Air. 391

(2nd) The Swan spectrum is that of an oxide of car'oon as it is only produced by carbon monoxide; and as this spectrum is changed at once into the carbon-oxide spectrum by admission of oxygen or by intense electric discharge, and, further, as the carbon-oxide spectrum is invariably given by carbon dioxide, there can be no doubt that

(3rd) The Swan spectrum is that of carbon monoxide, and the carbon oxide spectrum that of carbon dioxide.

We wish to express our indebtedness to Professor Ramsay for the great interest he bas taken in the experiments.

Spectroscopic Laburatory,

University College, London, June 1901.

XL. The Transmission of the Emanations of Phosphorus through Aiv and otler Media.-III. By C. BARUs*.

1. THE experiments of the present paper are made with an electrical method. They relate to the apparent decay of the ionization produced by phosphorus, in the lapse of time, for fixed distances apart of the condenser-plates; to the transmission of the ionization through layers of air and other media and barriers. They are thus preliminary to the subsequent experiments, in which the condenser and the colour-tube are combined and the coincident effects interpreted. I hope, moreover, to decide whether a form of radiation from phosphorus is presumable, or whether the case is merely that of an ionized gas exhaled by the slowly oxidizing body. I shall venture to treat the results in a simple and direct manner, in order to present them more consistently with my earlier papers $\dagger$ on the same subject, in which the attempt was made to arrive at the ion velocity of the phosphorus emanation by a non-electrical method, and therefore in the absence of an electrical field. Finally, I want in particular to ascertain whether, by giving less prominence to the decay of ions by mutual destruction within the element of volume, or otherwise, the phenomena may not be reasonably explained.

* Communicated br the Author.

† 'Science, xi. p. 201 (1900); xiii. p. 501 (1901); Physical Review, x. p. 257 (1900); and the current numbers of this Magazine. The ionization of the phosphorus emanation was known to Matteuci, and has been studied since by Neccari. It was rediscovered by Bidwell ('Nature,' Dec., p. 212, 1893). Cf. 'Nature,'lv. pp. 6, 125, 155 (1897) ; also xlix. p. 363 (1894). I believe to have been the first to point out its remarkable activity in producing condensation, and the substance is specially interesting to me because of this property. $C f$. Bulletin $\mathrm{N}$, 12 , U.S. Weather Bureau, Washington, 1895 . 